\title{
MODELO DE DESENVOLVIMENTO DE SERIOUS GAMES TIPO QUIZ BASEADO NA AVALIAÇÃO DA USABILIDADE
}

\author{
SÃO LUÍS/MA JULHO/2018
}

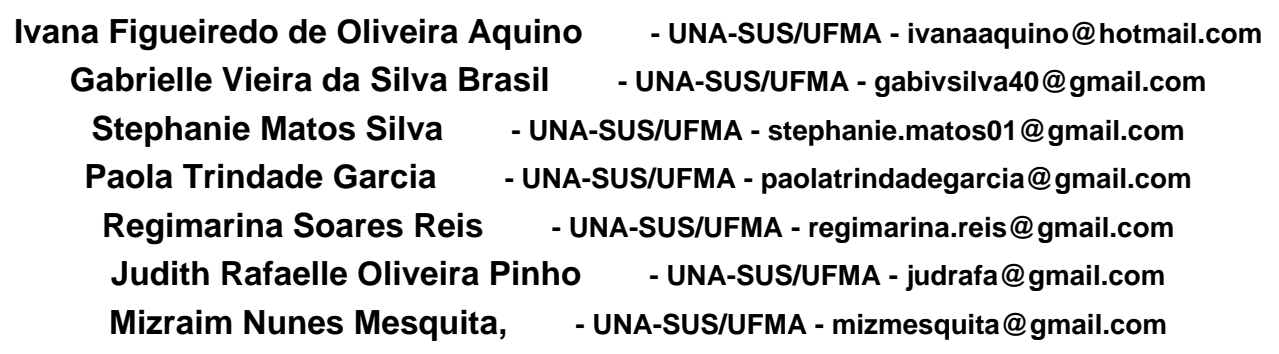

Tipo: Investigação Científica (IC)

Natureza: Descrição de Projeto em Andamento

Categoria: Pesquisa e Avaliação

Setor Educacional: EDUCAÇÃO MÉDIA E TECNOLÓGICA

\begin{abstract}
RESUMO
Atualmente, os jogos vêm se destacando por ir além do entretenimento, e por ter se tornado uma ferramenta poderosa no processo de ensino-aprendizagem. Fato que está relacionado ao seu poder motivacional na interação jogo-usuário. No entanto, se sua usabilidade não estiver adequada, a motivação do jogador será comprometida, afetando assim, a eficiência dessa ferramenta. Neste contexto, este estudo tem como objetivo avaliar a usabilidade da versão beta do game quiz de Gestão Pública em Saúde desenvolvido pela UNA-SUS/UFMA. O game foi avaliado por 12 experts da área de conhecimento de saúde, educação, informática e design. Primeiramente, os experts jogaram o game quiz e em seguida responderam o instrumento Meega a partir de uma escala de likert de 7 pontos. Através da análise dos dados, observou-se que a média geral da usabilidade do game em estudo foi de 4,58, que o classifica como bom. Assim, percebemos que precisamos aperfeiçoar alguns pontos quanto à usabilidade do game para realizar a publicação da versão alfa.
\end{abstract}

Palavras-chave: Serious Games. Educação em saúde. Usabilidade. 


\section{INTRODUÇÃO}

É inegável avanço no ramo da Tecnologia da Informação e Comunicação (TIC) tem chamado a atenção de muitos educadores para jogos eletrônicos, pois têm se demonstrado um recurso benéfico e promissor no processo de ensino-aprendizagem (PINTO; BOTELHO, 2013).

Os serious games são jogos educativos que abordam conhecimentos específicos, visando o ensino, o treinamento de novas habilidades ou a conscientização sobre questões importantes (MACHADO et al., 2011; PAIVA et al., 2013). Um serious game do tipo Quiz é composto de perguntas e respostas, que permite que o usuário aprenda de forma lúdica enquanto estabelececuma competição saudável com outros jogadores.

Apesar dos jogos serem mais comumente associados ao puro entretenimento, tem sido valorizado cada vez mais seu poder como ferramenta de ensino, devido apresentar características como motivação que o torna uma ferramenta educacional.

Ignorar estudos da usabilidade de um jogo em desenvolvimento certamente levará o jogador a frustração, prejudicando o principal fator que leva os jogos a serem procurados, seu caráter motivacional. Nos jogos sérios, este comprometimento pode destruir completamente o seu diferencial para uma ferramenta comum de trabalho, comprometendo então esse jogo como ferramenta alternativa de aprendizado.

Assim, é possível perceber a importância se se realizar a avaliação de usabilidade como etapa do desenvolvimento de um jogo, devendo haver uma constante avaliação desde o principio com especialistas.

Este estudo tem como objetivo avaliar a usabilidade da versão beta do game quiz de Gestão Pública em Saúde desenvolvido pela UNA-SUS/UFMA.

\section{REFERENCIAL TEÓRICO}

É inegável o expressivo crescimento de jogos produzidos com fins de educação na saúde, inclusive com a criação de áreas específicas de produção, como a dos jogos sérios (serious games) (PIRES; GOTTEMS; FONSECA, 2017).

O potencial pedagógico de jogos eletrônicos na educação, considerando suas inúmeras 
características positivas de interatividade, imersão, capacidade de adaptação e elemento lúdico, que são estruturadas por regras e metas e que possibilitam a aprendizagem por meio do feedback e resolução de problemas. (NOVAK, 2010)

Duas teorias de aprendizagem são muito relevantes atualmente para embasar o uso das novas mídias e tecnologias na educação: o construtivismo, que afirma que a construção do conhecimento se dá na interação ativa das pessoas com o ambiente e dessa teoria deriva o sócio-construtivismo, que defende a interação social como um caminho para a aprendizagem e a cognição situada que estabelece a aprendizagem e a formação do conhecimento como atividades dinâmicas, que estão em constante reavaliação para possibilitar ao aluno novas concepções de modelos de colaboração (BISSOLOTTI et al., 2014).

Considerando a diversidade de gêneros e funções dos jogos eletrônicos, o serious game têm despertado o interesse de muitos pesquisadores nas diversas áreas, como saúde, educação, ciências sociais, entre outras, ampliando seu uso com foco na educação. Esse tipo de jogo cada vez mais tem se destacado na indústria de softwares, ao assumir um papel fundamental como ferramenta pedagógica na educação, além de manter 0 caráter lúdico ou de entretenimento fortemente inerente dos jogos tradicionais (RIEMER; SCHRADER, 2015).

O jogo eletrônico é um sistema no qual o tomador de decisão (jogador) se engaja em um desafio artificial que é definido por regras e superação desse e a meta, e cujo resultado e objetivamente quantificável e incerto (ARAUJO; STEIN; ROMAO, 2012).

A Gamificação surge então com a proposta de aplicar elementos oriundos de jogos em atividades educacionais. Além da ludicidade, essa metodologia oferece a professores diversos recursos como sistemas feedback, que guiam o aluno no decorrer das tarefas através de instruções simples e objetivas que podem ajudar os discentes na compreensão de novos conceitos (MENEZES; BORTOLLI, 2016). Outro recurso apresentado por essa metodologia são os sistemas de pontuação, que podem ser usados para motivar os alunos a melhorar seu rendimento nas atividades e também permitem que professores acompanhem o progresso dos discentes.

No entanto, normalmente o uso e o sucesso de uma game digital depende do seu grau de usabilidade. Segundo Karray et al. (2008), a usabilidade é caracterizada com a variedade e o grau com que as funcionalidades do sistema podem ser utilizadas eficientemente, permitindo a realização das tarefas de forma eficaz e intuitiva. A eficiência real de um sistema é alcançada quando existe um equilíbrio entre a 
funcionalidade e a usabilidade.

Dentre as características de usabilidade definidas por Nielsen (2012), estão a facilidade em realizar as tarefas básicas; a eficiência ao realizar estas tarefas; a facilidade ao reutilizar recursos; o reestabelicmento de serviços aos erros cometidos e a satisfação com o uso. Diante deste contexto, a avaliação de usabilidade de games é fundamental para garantir uma boa experiência aos usuários.

\section{PROCEDIMENTOS METODOLÓGICOS}

- Escalas de avaliação

O game foi avaliado a partir do instrumento Meega (FU et al., 2009).

As dimensões de análise foram: concentração, clareza nos objetivos, feedback, desafio, autonomia, imersão, interação social e usabilidade. Neste estudo, iremos abordar apenas a dimensão usabilidade.

Essa avaliação foi realizada por 12 experts que dominam conhecimento na área de saúde, educação, informática e design. Os itens foram avaliados a partir de uma escala de likert de 7 pontos e acrescentou-se um item para as situações nas quais o avaliador não observasse o item em questão no game, o que o tornava impossível de avaliar.

Abaixo tem-se a definição de cada um dos pontos da escala:

1. Extremamente fraco: deve ser a opção para quando o elemento avaliado apresentar qualidade extremamente inferior ao esperado para um game ou para o que costuma ser produzido e/ou apresentado em produtos semelhantes.

2. Moderadamente fraco: deve ser a opção para quando o elemento avaliado apresentar qualidade muito inferior ao esperado para um game ou para o que costuma ser produzido e/ou apresentado em produtos semelhantes.

3. Fraco: deve ser a opção para quando o elemento avaliado apresentar qualidade inferior ao esperado para um game ou para o que costuma ser produzido e/ou apresentado em produtos semelhantes.

4. Indiferente: deve ser a opção para quando o avaliador não tem certeza, clareza ou conhecimento no item específico avaliado.

5. Forte: deve ser a opção para quando o elemento avaliado se apresentar dentro dos padrões esperado para um game ou para o que costuma ser produzido e/ou apresentado em produtos semelhantes. 
6. Moderadamente forte: deve ser a opção para quando o elemento avaliado apresentar qualidade acima do esperado para um game ou para o que costuma ser produzido e/ou apresentado em produtos semelhantes.

7. Extremamente forte: deve ser a opção para quando o elemento avaliado apresentar qualidade muito acima do esperado para um game ou para o que costuma ser produzido e/ou apresentado em produtos semelhantes.

8. Não foi possível avaliar: opção para quando o elemento em questão não aparece no game, portanto não pode ser avaliado.

- Seleção de experts

Por se tratar de uma área de conhecimento nova, o número de experts é restrito e a forma de disponibilização do game (smartphones ou tablets) impossibilitou a inclusão de experts fora da cidade de São Luís.

Desse modo, solicitou-se a indicação de experts aos setores de programação e desing (gráfico e instrucional) da UNASUS/UFMA que atendessem os seguintes critérios: Graduação em qualquer área do conhecimento, experiência na área de design instrucional, gráfico, web design ou programação de games.

Isso resultou na seleção de 12 experts.

- Coleta de dados

A coleta de dados foi realizada mediante agendamento, em ambiente silencioso. Foi disponibilizado smartphone com sistema operacional Android, processador quadri-core $1,2 \mathrm{GHz}$, tela de 4,5 polegadas para que o expert pudesse avaliar o jogo.

- Análise de dados

Os dados foram digitados e analisados no programa Excel® a partir da média, frequência e desvio padrão das respostas dos experts. Foram excluídos os itens com frequência de resposta "não foi possível avaliar" superior a $50 \%$.

As respostas que foram atribuídas 4 como avaliação não foram consideradas no cálculo da média, uma vez que seriam itens que os experts não se consideravam aptos para analisar. 
- Classificação

Para classificação dos itens avaliados utilizou-se a seguinte escala:

Média 6 - 7: excelente

Média 4 - 5,9: bom

Média 2 - 3,9: regular

Média <2: insuficiente

\section{RESULTADOS E DISCUSSÃO}

Após análise de identificação dos 12 experts, foi possível observar a média e o desviopadrão quanto a idade, tempo de graduação e tempo de trabalho na área de design (Figura 1).

\begin{tabular}{lll}
\hline Descrição & Média & Desvio Padrão \\
\hline Idade & 28,66 & 3,62 \\
Tempo de formação (graduação) & 5,30 & 4,01 \\
Tempo de trabalho na área de design & 2,79 & 1,90 \\
\hline
\end{tabular}

Figura 1. Características dos avaliadores.

Ainda sobre as características da equipe de experts, se percebeu que a maioria (33,33\%) possuíam formação, segundo classificação da Coordenação de Aperfeiçoamento de Pessoal de Nível Superior (CAPES), na área de ciências da saúde (figura 2).

\begin{tabular}{ll}
\hline Descrição & Frequência (\%) \\
\hline Ciências da computação & 25 \\
Ciências da saúde & 33,33 \\
Ciências sociais & 25 \\
Ciências humanas & 16,67
\end{tabular}


Figura 2. Descrição de frequência por área de formação dos avaliadores

$\mathrm{Na}$ figura 3 estão dispostos os resultados referente a dimensão de usabilidade. A maioria dos itens avaliados obtiveram médias classificadas como bom e um item que questiona se o jogo é fácil de usar, foi classificado como excelente. No entanto, o item que questiona se o jogo permite personalizar a aparência (fonte e/ou cor) conforme a minha necessidade, apresentou média classificada como insuficiente (figura 3).

\begin{tabular}{|c|c|c|}
\hline Descrição do item avaliado & Média & $\begin{array}{l}\text { Desvio } \\
\text { Padrão }\end{array}$ \\
\hline $\begin{array}{l}\text { O design do jogo é atraente (interface, gráficos, } \\
\text { tabuleiro, cartas, etc.) }\end{array}$ & 5,00 & 1,65 \\
\hline Os textos, cores e fontes combinam e são consistentes & 4,45 & 1,43 \\
\hline $\begin{array}{l}\text { Eu precisei aprender poucas coisas para poder começar } \\
\text { a jogar o jogo }\end{array}$ & 5,00 & 2,27 \\
\hline Aprender a jogar este jogo foi fácil para mim & 5,81 & 1,60 \\
\hline $\begin{array}{l}\text { Eu acho que a maioria das pessoas aprenderiam a jogar } \\
\text { este jogo rapidamente }\end{array}$ & 5,50 & 1,56 \\
\hline Eu considero que o jogo è fácil de jogar & 6,00 & 0,95 \\
\hline As regras do jogo são claras e compreensiveis & 4,45 & 2,69 \\
\hline $\begin{array}{l}\text { As fontes (tamanho e estilo) utilizadas no jogo são } \\
\text { legiveis }\end{array}$ & 3,66 & 1,66 \\
\hline As cores utilizadas no jogo são compreensiveis & 5,16 & 1,74 \\
\hline $\begin{array}{l}\text { O jogo permite personalizar a aparência (fonte e/ou cor) } \\
\text { conforme a minha necessidade }\end{array}$ & 1 & 0 \\
\hline O jogo me protege de cometer erros & 4,44 & 1,74 \\
\hline $\begin{array}{l}\text { Quando eu cometo um erro é fácil de me recuperar } \\
\text { rapidamente }\end{array}$ & 4,47 & 2,04 \\
\hline
\end{tabular}

Figura 3. Descrição de média e desvio padrão da dimensão usabilidade.

A média geral da usabilidade do game quiz foi 4,58, que o classifica como bom.

A usabilidade é considerada a qualidade da interação do usuário com a interface/game. Problemas que comprometem ou dificultam a qualidade dessa relação levam ao desempenho deficiente, podendo ocasionar feedback negativos como comprometimento da aprendizagem dos conteúdos até à rejeição pelo software. (KRUG, 2005; REATEGUI,2007).

Krug (2005) ressalta a necessidade de um game ter uma boa usabilidade, para isso precisa ser de fácil aprendizagem, eficiente no uso e fácil de ser lembrado. Podemos destacar que no caso do jogo estudado, umas das maiores médias $(5,0)$ foi justamente 
quanto ao fácil manuseio, pelos os experts relataram que precisaram aprender poucas coisas para começar a jogar o jogo.

No processo de desenvolvimento do software educativo é fundamental que se conheça a clientela a que se destina, pois, o conhecimento do perfil do usuário permitirá a compreensão do contexto profissional em que está inserido, a forma do jogo e abordagem mais adequada para definir o tipo de aprendizagem deste público alvo (NOVAK,2010).

Os testes de usabilidade são metodologias que geram informações que dão suporte ao desenvolvimento do jogo ao unificar a visão do especialista em usabilidade aos dados experimentais dos problemas encontrados no jogo. A avaliação com especialista é uma forma rápida e efetiva que possibilita consertos de numerosos pequenos problemas antes que estes cheguem ao teste com o usuário e prejudique sua experiência (LIMA; BUENA; PERRY, 2017). Igualmente se optou por fazer nesse estudo, no qual os resultados são referente a uma avaliação de uma versão beta, para que através destes resultados obtidos, se realize os ajustes necessário para que o game seja classificado como excelente para ser lançado nas plataformas digitais.

\section{CONSIDERAÇÕES FINAIS}

O game é uma ferramenta pedagógica que possibilitam a aprendizagem de maneira lúdica, no entanto o seu grau de usabilidade vai impactar na eficiência dessa ferramenta.

Com isso, a necessidade de se avaliar a usabilidade do game em estudo em sua versão beta, o qual foi classificado como bom. A partir desse resultado, a equipe da UNASUS/UFMA está revendo e aperfeiçoando cada dimensão da usabilidade estudada para que o game alcance a classificação excelente (média entre 6 e 7).

Desta forma, a instituição disponibilizará nas plataformas digitais para acesso gratuito, quando o game estiver com a versão alfa.

\section{REFERÊNCIAS}

ARAUJO, M.H.; STEIN, M.; ROMAO, J.J.S. Jogo e serious games: conceito e bons princípios para analise do jogo SpaceCross, da Volkswagen. SBC - Proceedings of SBGames. 2012.

BISSOLOTTI, K.; NOGUEIRA, H.G.; PEREIRA, A.T.C. Potencialidades das mídias 
sociais e da gamificação na educação a distancia. CINTED - Novas Tecnologias na Educação, v. 12, n. 2, 2014.

FU, F.L.; SU, R.C.; YU, S.C. EGameFlow: A scale to measure learners' enjoyment of elearning games. Computers and Education, v. 52, n. 1, p. 101-112, 2019.

KARRAY, F. et al. Human-Computer Interaction: Overview on State of the Art. Pattern Analysis and MAchine Intelligence Lab., Departamento $f$ Electrical and Computer Engineering Univsersity of Waterloo, Waterloo, Canadá, 2008.

KRUG, S. Don't make me think: a commom sense approach to web usability. $2^{\mathrm{a}}$ ed. [S.I.]: New Riders Press, 2005.

MACHADO, L.S. et al. Serious games baseados em realidade virtual para educação médica. Rev bras educ med. 2011? 35(2): 254-62.

NIELSEN, J. Unabity 101: Introduction to Usability. Disponível em:

NOVAK, J. Desenvolvimento de games. São Paulo: Cengage Learning, 2010.

PAIVA, P.V.F. et al. Uma proposta de serious game para o ensino de biossegurança em odontologia. Pesq Bras Odontoped Clin Integr. 2013? 13(2): 135-39.

PINTO, I.M.;BOTELHO, S.S.C. Ambientes tecnológicos lúdicos de autoria (ATLA): desenvolvendo espaços de criação e experimentação para o aprendizado. Rev. Teoria e Prática da Educação. 2013; 16(1): 81-96.

PIRES, M.R.G.M.; GOTTEMS, L.B.D.; FONSECA, R.M.G.S. recriar-se lúdico no desenvolvimento de jogos na saúde: referências teórico-metodológicas à produção de subjetividades críticas. Texto contexto - enferm., Florianópolis, v. 26, n. 4, e2500017, 2017.

REATEGUI, E. Interfaces para softwares educativos. Renote, Porto Alegre, v. 5, n. 1, 2007.

RIEMER, Valentin; SCHRADER, Claudia. Learning with quizzes, simulations, and adventures: Students' attitudes, perceptions and intentions to learn with different types of serious games. Computers \& Education, 2015. 
